\title{
Tolerância do Sorgo Granífero ao Herbicida Tembotrione ${ }^{1}$
}

\author{
Tolerance of Grain Sorghum to Tembotryone
}

\author{
DAN, H.A. ${ }^{2}$, BARROSO, A.L.L. ${ }^{3}$, DAN, L.G.M. ${ }^{4}$, PROCÓPIO, S.O. ${ }^{5}$, FERREIRA FILHO, W.C. ${ }^{6}$ e \\ MENEZES, C.C.E. ${ }^{6}$
}

\begin{abstract}
RESUMO - O sorgo granifero é uma espécie de destaque perante as culturas utilizadas em sucessão na região dos cerrados. No entanto, não há nenhum herbicida seletivo a essa cultura registrado para o controle de gramineas infestantes. Dessa forma, o presente trabalho teve por objetivo avaliar a seletividade do herbicida tembotrione aplicado em pós-emergência da cultura do sorgo granifero cultivar AG-1040. O ensaio foi disposto no delineamento de blocos ao acaso em esquema fatorial $5 \times 3$, com quatro repetições. Os tratamentos corresponderam a cinco doses do herbicida tembotrione $(0,42,88,126$ e $168 \mathrm{~g}$ de i.a. ha-1), aplicados em três estádios fenológicos da cultura: três, cinco e oito folhas completamente expandidas. Foram avaliados os niveis de intoxicação, a altura das plantas, a biomassa seca da parte aérea e o rendimento de grãos da cultura. O herbicida tembotrione apresentou maior intoxicação quando aplicado nos estádios mais precoces da cultura do sorgo. Mesmo com os diferentes niveis de seletividade, que podem variar em função da dose e da época de aplicação, o cultivar de sorgo estudado apresentou tolerância satisfatória ao tembotrione, sugerindo potencial de utilização desse herbicida nessa cultura.
\end{abstract}

Palavras-chave: Sorghum bicolor, seletividade, inibidores de HPPD.

\begin{abstract}
Grain sorghum is a prominent species among the crops used in succession in the Brazilian savanna region. However, no herbicide with selectivity to sorghum is currently registered for grass weed control. Thus, this study aimed to evaluate the selectivity of tembotrione applied in post-emergence on grain sorghum crop (cultivar AG-1040). The experiment was laid out in a randomized block design in a $5 \times 3$ factorial with four replicates. The treatments were five tembotrione doses, 0, 42, 88, 126 and $168 \mathrm{~g}$ a.i. ha $\mathrm{h}^{-1}$, applied at three phenological stages of the crop: three, five, and eight expanded leaves. The variables evaluated were phytotoxicity level, plant height, shoot dry biomass and crop grain yield. Tembotrione showed higher phytotoxicity potential when applied at the early stages of sorghum growth. In spite of the different selectivity levels, which may vary depending on the dose and time of application, the sorghum cultivar studied showed a satisfactory tolerance to tembotrione. The results obtained indicate that this herbicide has the potential to be used in grain sorghum crop.
\end{abstract}

Keywords: Sorghum bicolor, selectivity, HPPD-inhibiting herbicides.

\section{INTRODUÇÃO}

O sorgo (Sorghum bicolor) constitui-se em uma espécie de verão muito utilizada na Índia, nos Estados Unidos e alguns países da África, devido a seu alto valor nutritivo, tanto para alimentação humana (grãos) como animal (forragens e grãos) (Dahlberg et al., 2004). No

1 Recebido para publicação em 25.8.2009 e na forma revisada em 3.9.2010.

2 Discente do Programa de Pós-Graduação em Agronomia, Universidade Estadual de Maringá - UEM/NAPD, Av. Colombo 5790, 87020-900 Maringá-PR, <halmeidadan@gmail.com>; ${ }^{3}$ Docente do curso de Pós-Graduação em Produção Vegetal, Universidade de Rio Verde - FESURV, Caixa Postal 104, 75901-970 RioVerde-GO, <all_barroso@hotmail.com>; ${ }^{4}$ Mestranda do Programa de Pós-Graduação em Agronomia, UEM/NUPAGRI, <lilian-agronoma@hotmail.com>; ${ }^{5}$ Pesquisador, Embrapa Tabuleiros Costeiros, 49025-040 Aracaju-SE, <procopio@cpatc.embrapa.br>; ${ }^{6}$ Pesquisadores do Centro Tecnológico Comigo, Rio Verde-GO, <wandercruvinel@brturbo.com.br>; <carlosmenezes@comigo.com.br>.

Planta Daninha, Viçosa-MG, v. 28, n. 3, p. 615-620, 2010 
Brasil, o sorgo tem ganhado destaque principalmente como cultura de segunda safra, sendo indicada como alternativa viável na substituição do milho como cultura de sucessão, tanto para formação de palha para o sistema de plantio direto quanto para a produção de grãos e forragem (Gontijo Neto et al., 2002).

Como em qualquer outra cultura, a matocompetição pode interferir negativamente no seu rendimento final. Estima-se que a convivência das plantas daninhas com o sorgo granifero durante as quatro primeiras semanas após a emergência pode promover reduções de 40 a $97 \%$ no rendimento de grãos (Tamado et al., 2002). Segundo Norris (1980), a presença de 175 plantas por $\mathrm{m}^{2}$ de Echinochloa crus-galli pode reduzir a produtividade do sorgo granífero em 52\%. Para Moore et al. (2004), o incremento de uma planta de Amaranthus palmeri por $\mathrm{m}^{2}$ pode proporcionar reduções de até $1,8 \%$ no rendimento dessa cultura. Em relação ao sorgo forrageiro, a matocompetição pode reduzir de 18 a $80 \%$ a produção de forragem (Andres et al., 2009).

Apesar de ser uma cultura de grande destaque para a produção de grãos na região dos cerrados, poucos são os estudos referentes à seletividade de herbicidas para essa espécie (Abit et al., 2009), evidenciando a importância de novas pesquisas, já que o maior agravante para essa cultura é a dificuldade no controle de gramineas invasoras. De acordo com Archangelo et al. (2002), um dos grandes entraves à expansão da cultura do sorgo tem sido a dificuldade no manejo de plantas daninhas, em razão da sensibilidade dessa cultura aos herbicidas graminicidas comercializados no Brasil.

Dentre os herbicidas de ação graminicida e latifolicida com potencial para utilização em pós-emergência da cultura do sorgo, destacam-se os herbicidas inibidores de carotenoides de aplicação em pós-emergência, principalmente os que inibem a enzima hydroxyphenylpyruvate dioxygenase (HPPD) (Miller \& Regehr, 2002; Abit et al., 2009). Esses herbicidas promovem branqueamento nas folhas, como resultado da degradação oxidativa da clorofila e das membranas fotossintéticas (Mitchell et al., 2001; Armel et al., 2003; Grossmann \& Ehrhardt, 2007).
Algumas espécies cultivadas, como o mi1ho, apresentam tolerância a esses herbicidas. A seletividade dos herbicidas inibidores da HPPD ocorre pelo rápido metabolismo de suas moléculas, devido principalmente à ação da hemoproteína citocromo P-450 (Mitchell et al., 2001; Pataky et al., 2008).

O herbicida tembotrione, lançado recentemente no Brasil para uso na cultura do milho em pós-emergência, vem apresentando desempenho satisfatório no controle de plantas daninhas, sobretudo de gramineas. Segundo Waddington \& Young (2006), esse herbicida apresenta o safener isoxadifen-ethyl, que confere maior seletividade para as culturas de milho e milho-pipoca. Ao avaliar os herbicidas mesotrione, topramesone e tembotrione no controle de plantas daninhas na cultura do milho, Bollman et al. (2008) constataram que o tembotrione causou menores percentuais de injúria quando comparado aos demais.

O sorgo, tradicionalmente, apresenta maior suscetibilidade a herbicidas quando comparado ao milho, tanto que comumente é utilizado como planta indicadora de herbicidas, principalmente de graminicidas. Esse comportamento limita o uso do controle químico como principal ferramenta no manejo de plantas daninhas na cultura. A maior parte dos trabalhos envolvendo seletividade de herbicidas inibidores da HPPD ao sorgo foi realizada com mesotrione (Miller \& Regehr, 2002; Horky \& Martin, 2005; Abit et al., 2009), todos fora do Brasil.

Para que a cultura do sorgo continue se expandindo no Brasil, é de fundamental importância a identificação de herbicidas de aplicação em pós-emergência com ação sobre gramineas que apresentem seletividade a essa cultura. Segundo Stahlman \& Wicks (2000), a maioria dos herbicidas registrados para uso na cultura do sorgo foi inicialmente desenvolvida para uso em culturas de maior escala, particularmente o milho. Nesse contexto, objetivou-se neste trabalho avaliar a seletividade do herbicida tembotrione, aplicado em pós-emergência, em três estádios de desenvolvimento do sorgo granífero.

\section{MATERIAL E MÉTODOS}

O experimento foi conduzido durante a safra 2008/2009, no município de Rio Verde-GO, 
cujas coordenadas geográficas são: latitude de $17^{\circ} 47^{\prime} 24^{\prime \prime} \mathrm{S}$, longitude de 50॰56’31" W e altitude de 698 metros. O clima regional classificado pelo sistema internacional de Köppen é do tipo CWA, úmido e inverno seco, com precipitação média anual de $1.500 \mathrm{~mm}$ e temperatura média anual de $25^{\circ} \mathrm{C}$.

O solo da área experimental é classificado como Latossolo Vermelho eutrófico e possui $450 \mathrm{~g} \mathrm{~kg}^{-1}$ de argila, $60 \mathrm{~g} \mathrm{~kg}^{-1}$ de silte e $490 \mathrm{~g} \mathrm{~kg}^{-1}$ de areia, com saturação por bases de $53 \%$. Antes da semeadura do sorgo, que ocorreu logo após a colheita da soja, a área foi manejada com $1.440 \mathrm{~g} \mathrm{ha}^{-1}$ de glyphosate.

O cultivar de sorgo granífero AG-1040 foi semeado no espaçamento de $0,5 \mathrm{~m}$ de forma mecanizada, obtendo-se uma população final de 90 mil plantas ha-1 ${ }^{-}$No momento da semeadura, realizou-se uma adubação de base com $30 \mathrm{~kg} \mathrm{ha}^{-1}$ de $\mathrm{P}_{2} \mathrm{O}_{5}$ (superfosfato simples), $20 \mathrm{~kg} \mathrm{ha}^{-1}$ de $\mathrm{K}_{2} \mathrm{O}$ (cloreto de potássio) e $20 \mathrm{~kg} \mathrm{ha}^{-1}$ de $\mathrm{N}$ (sulfato de amônia).

As parcelas foram dimensionadas numa área de $21 \mathrm{~m}^{2}$, e o ensaio, instalado no delineamento de blocos casualizados, com quatro repetições, em esquema fatorial $5 \times 3$, correspondendo a cinco doses de tembotrione $\left(\operatorname{Soberan}^{\circledR}\right)\left(0,42,88,126\right.$ e 168 g de i.a. ha $\left.{ }^{-1}\right)$, aplicadas em três estádios fenológicos da cultura do sorgo: estádio 1 (plantas com três folhas, 15 dias após a emergência); estádio 2 (plantas com cinco folhas, 23 dias após a emergência); e estádio 3 (plantas com oito folhas, 31 dias após a emergência).

A aplicação dos tratamentos herbicidas foi feita utilizando-se um pulverizador costal com pressurização por $\mathrm{CO}_{2}$, munido de barra de $3 \mathrm{~m}$, contendo quatro pontas de pulverização do tipo TT 110-02 (0,5 m entre pontas), aplicando volume de calda equivalente a $100 \mathrm{~L} \mathrm{ha}^{-1}$. As condições ambientais no momento das aplicações eram as seguintes: estádio 1 (temperatura média de $27,2{ }^{\circ} \mathrm{C}$, UR média de $74 \%$ e velocidade do vento média de $2,1 \mathrm{~km} \mathrm{~h}^{-1}$ ); estádio 2 (temperatura média de $26,2^{\circ} \mathrm{C}$, UR média de $88 \%$ e velocidade do vento média de $1,4 \mathrm{~km} \mathrm{~h}^{-1}$ ); e estádio 3 (temperatura média de $25,7^{\circ} \mathrm{C}$, UR média de $77 \%$ e velocidade do vento média de $2,8 \mathrm{~km} \mathrm{~h}^{-1}$ ). Todas as aplicações foram iniciadas no mesmo horário (7h30), periodo que reuniu as melhores condições climáticas para as aplicações.
As avaliações de fitointoxicação foram realizadas aos 7 e 21 dias após a aplicação dos tratamentos (DAA), utilizando-se escala percentual de 0 a $100 \%$, em que 0 representa ausência de sintomas e $100 \%$ a morte de todas as plantas. Aos 60 dias após a emergência das plantas, determinou-se o acúmulo de biomassa seca da parte aérea; para isso, foram coletadas 10 plantas ao acaso de cada parcela, sendo esse material seco em estufa com circulação de ar a $65^{\circ} \mathrm{C}$ durante um período de 72 horas e imediatamente pesado em balança analítica.

Ao final do ciclo da cultura foi avaliada a altura das plantas, com uma trena graduada, sendo referenciada a distância do colo da planta à extremidade final da panícula. A produtividade de grãos foi determinada através da colheita manual das panículas das plantas presentes na área útil da parcela de $6 \mathrm{~m}^{2}$; logo após a colheita, o material foi trilhado, pesado e a umidade dos grãos corrigida para $13 \%$.

Os resultados referentes aos níveis de fitointoxicação foram submetidos a uma transformação $(\sqrt{ } \mathrm{x}+1)$ para seguir os pressupostos necessários à análise de variância, que foi realizada com o programa estatístico Sisvar $(p \geq 0,05)$. Foram ajustados modelos lineares de regressão para as variáveis que apresentaram significância, utilizando-se posteriormente o programa Sigma Plot versão 10.0 para a confecção das curvas de regressão.

\section{RESULTADOS E DISCUSSÃO}

Houve interação significativa entre as doses de tembotrione e os estádios de desenvolvimento do sorgo granífero, em relação às duas avaliações de fitointoxicação, cujos resultados podem ser observados na Figura 1. Aos sete dias após a aplicação (DAA), foi observado que os níveis máximos de intoxicação apresentados pela cultura foram de 59, 46 e $38 \%$, respectivamente, para aplicações realizadas no momento em que as plantas encontravam-se com 3,5 e 8 folhas completamente expandidas (Figura 1A), sugerindo que o cultivar de sorgo AG-1040 apresenta maior sensibilidade nas aplicações realizadas nos estádios mais precoces. Miller \& Regehr (2002) e Abit et al. (2009) observaram que alguns genótipos de sorgo granífero apresentaram 

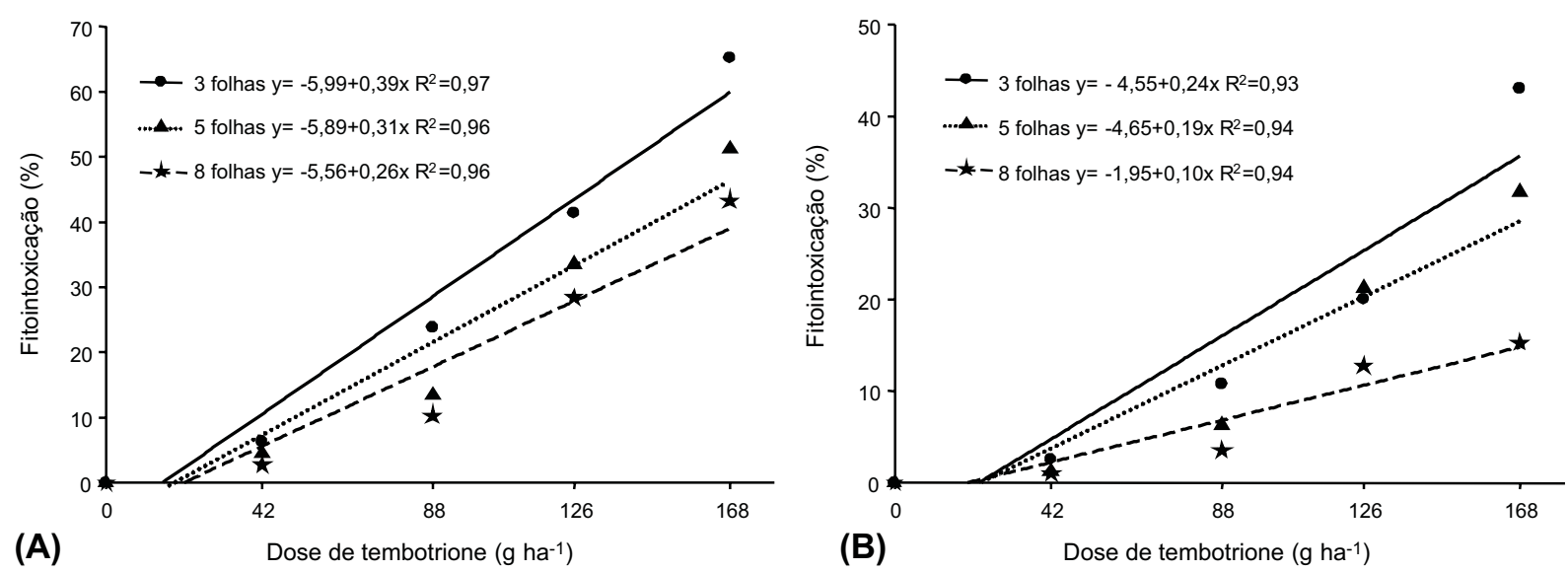

Figura 1 - Intoxicação em plantas de sorgo granífero aos 7(A) e 21(B) dias após a aplicação de diferentes doses do tembotrione, em três estádios da cultura.

$60 \%$ de fitointoxicação quando submetidos ao herbicida mesotrione (inibidor da HPPD) no estádio de quatro folhas. Durante as avaliações visuais, o sintoma mais pronunciado foi o branqueamento nas folhas ou albinismo algumas vezes rosados ou violáceos, semelhantes aos sintomas descritos por Felix \& Doohan (2005) e Abit et al. (2009).

Segundo Grossmann \& Ehrhardt (2007), a inibição da sintese de carotenoides causada pela ação do herbicida leva à decomposição da clorofila pela luz, como resultado da perda da fotoproteção fornecida pelos carotenoides, resultando na degradação oxidativa da clorofila e, em casos mais extremos, na oxidação das membranas celulares.

Apesar da ligeira recuperação dos sintomas aos 21 DAA, a tendência observada na avaliação aos 7 DAA foi mantida, indicando que aplicações realizadas em estádios mais precoces de desenvolvimento do sorgo mantiveram os maiores niveis de fitotoxicidade (Figura 1B).

Comparando os coeficientes angulares dos modelos lineares ajustados aos 21 DAA (Figura 1B), observa-se que, embora em todos os casos a porcentagem de fitointoxicação seja diretamente relacionada à dose aplicada de tembotrione, plantas que receberam o herbicida no estádio de três folhas apresentaram incrementos sobre a porcentagem de fitointoxicação, com uma taxa aproximadamente duas vezes maior do que a aplicação no estádio de cinco folhas, indicando que as plantas em estádios mais avançados de desenvolvimento toleram mais a ação desse herbicida. Ressalva-se que não foi constatada redução no estande de plantas (dados não apresentados).

Ao analisar os percentuais de acúmulo da biomassa seca da parte aérea (Figura 2), constata-se que as maiores reduções foram obtidas quando a aplicação do herbicida ocorreu no estádio mais precoce (três folhas). Durante esse período, a redução foi duas vezes mais acentuada, quando comparada com as aplicações realizadas em 5 e 8 folhas; no entanto,

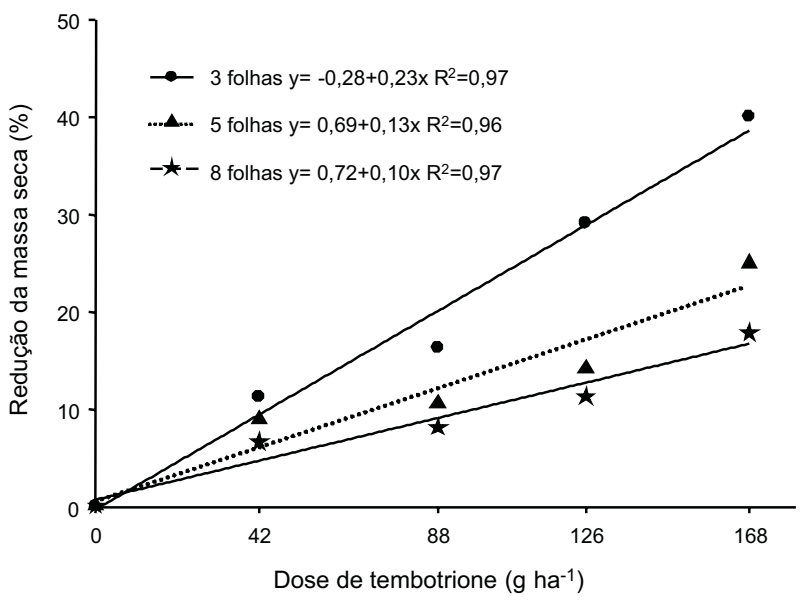

Figura 2 - Redução do acúmulo de massa seca da parte aérea de plantas de sorgo em função da aplicação de diferentes doses de tembotrione, em três estádios da cultura. 
os efeitos sobre a biomassa seca estão diretamente relacionados com o incremento da dose. Abit et al. (2009) constataram que todos os 85 híbridos de sorgo avaliados obtiveram reduções significativas no acúmulo de biomassa seca após a exposição ao mesotrione - herbicida que apresenta estrutura química muito próxima e mesmo modo de ação que o tembotrione (Mitchell et al., 2001).

Esse fato mostra que plantas menos desenvolvidas possuem menor capacidade de recuperação das injúrias causadas pelo tembotrione e que isso repercute diretamente sobre o acúmulo de biomassa seca, podendo representar um fator negativo para o cultivo de sorgo visando à produção de forragem, necessitando assim de maior cautela em relação à dose e época de aplicação desse herbicida.

A variável-resposta altura de plantas seguiu a mesma tendência das demais já discriminadas, em que a utilização de tembotrione apresentou maior potencial supressor quando a aplicação ocorreu no estádio mais precoce do sorgo (Figura 3). Observa-se que a redução na altura das plantas apresentou-se de forma diretamente proporcional à dose utilizada na aplicação. Em aplicações tardias (estádios de 5 e 8 folhas) essa variável foi pouco influenciada pela ação do tembotrione. Comparando os coeficientes angulares dos modelos lineares ajustados (Figura 3), observou-se que, embora em todos os casos a porcentagem de redução da altura seja diretamente relacionada à dose aplicada de tembotrione, plantas que receberam o herbicida no estádio de três folhas apresentaram incrementos sobre a porcentagem de redução numa taxa aproximadamente três vezes maior do que aquelas que receberam a aplicação no estádio de cinco e oito folhas. Archangelo et al. (2002) constataram que aplicações mais precoces de atrazine + metolachor (plantas de sorgo com duas folhas) provocaram maior toxicidade à cultura, decrescendo com aplicações mais tardias (plantas com quatro e seis folhas). É importante frisar que a altura das plantas é um fator primordial no processo de colheita dos grãos, já que na região dos cerrados essa espécie é colhida mecanicamente.

A intoxicação causada pelo uso do tembotrione proporcionou reduções significativas sobre rendimento de grãos da cultura (Figura 4). Dentro do intervalo de doses estudado, as reduções com a utilização da maior dose (168 $\left.\mathrm{g} \mathrm{ha}^{-1}\right)$ chegaram a 25, 16 e $15 \%$ para as aplicações realizadas com 3, 5 e 8 folhas expandidas, respectivamente. Esses resultados evidenciam que as aplicações precoces intensificam a redução da produtividade do cultivar de sorgo AG-1040.

$\mathrm{Na}$ cultura do milho, o tembotrione é recomendado em doses que variam de 75,6 a $100,8 \mathrm{~g} \mathrm{ha}^{-1}$. Considerando a menor dose

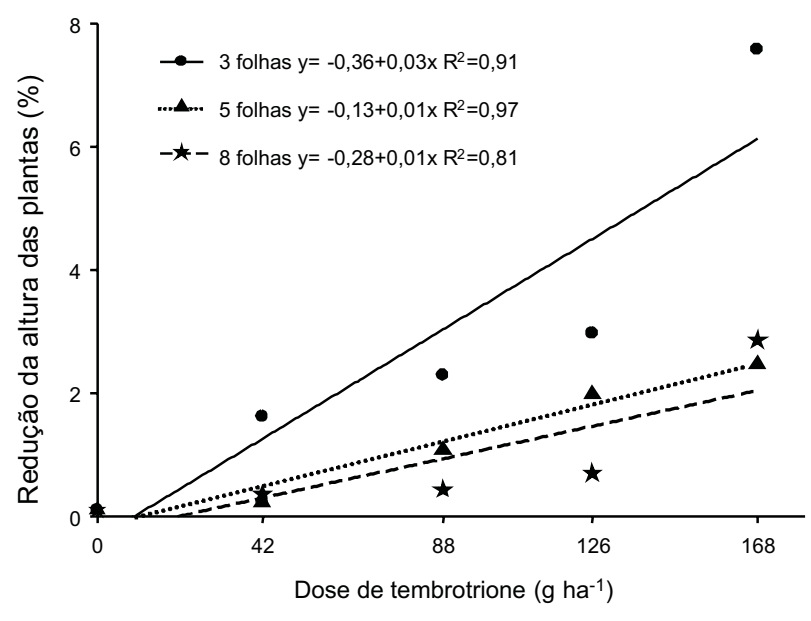

Figura 3 - Redução da altura das plantas de sorgo em função da aplicação de diferentes doses de tembotrione, em três estádios da cultura.

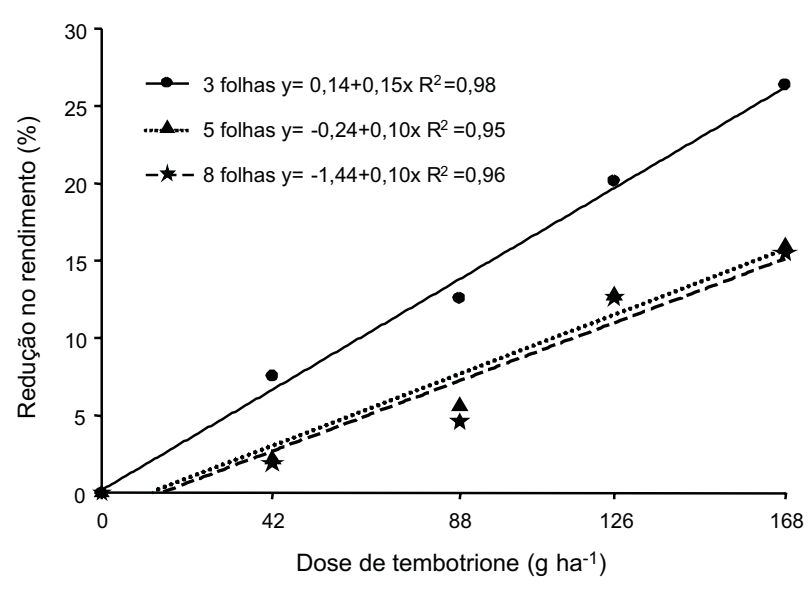

Figura 4 - Redução do rendimento de grãos da cultura do sorgo em função da aplicação de diferentes doses de tembotrione, em três estádios da cultura.

Planta Daninha, Viçosa-MG, v. 28, n. 3, p. 615-620, 2010 
recomendada $\left(75,6 \mathrm{~g} \mathrm{ha}^{-1}\right)$, é possivel constatar que o maior percentual de redução na produtividade de grãos foi de $11,4 \%$, quando as aplicações foram realizadas com três folhas. Com cinco e oito folhas, as reduções atingiram valores de 7,3 e $6,1 \%$, respectivamente.

Esses resultados indicam um potencial de uso desse herbicida na cultura do sorgo granífero; contudo, são necessários estudos com outros cultivares de sorgo para complementação das informações sobre seletividade desse herbicida.

Apesar dos diferentes niveis de seletividade observados no experimento, é importante salientar que a interferência causada pelas plantas daninhas pode ocasionar perdas de até $97 \%$ sobre o rendimento de grãos da cultura do sorgo (Tamado et al., 2002), justificando a necessidade do controle das invasoras. Além disso, o produtor também deve estar atento à relação custo-benefício ao adotar determinada medida de controle das plantas daninhas.

O herbicida tembotrione apresentou maior potencial de fitotoxicidade quando aplicado nos estádios mais precoces do cultivar de sorgo AG-1040. Mesmo com os diferentes niveis de seletividade, que podem variar em função da dose e da época utilizada para a aplicação, o cultivar de sorgo estudado apresentou tolerância satisfatória ao tembotrione, demonstrando potencial de utilização nessa cultura.

\section{LITERATURA CITADA}

ANDRES, A. et al. Períodos de interferência de plantas daninhas na cultura do sorgo forrageiro em terras baixas. Planta Daninha, v. 27, n. 2, p. 229-234, 2009.

ABIT, J. M. et al. Differential response of grain sorghum hybrids to foliar-applied mesotrione. Weed Technol., v. 23, n. 1, p. $28-33,2009$

ARCHANGELO, E. R. et al. Tolerância do sorgo forrageiro ao herbicida Primestra SC. R. Bras. Milho Sorgo, v. 1, n. 2 , p. $59-66,2002$

ARMEL, G. R. et al. Mesotrione combinations in no-till corn (Zea mays). Weed Technol., v. 17, n. 3, p. 111-116, 2003

BOLLMAN, J. D. et al. Efficacy and tolerance to HPPDinhibiting herbicides in sweet corn. Weed Technol., v. 22, n. 4, p. 666-674, 2008.

Planta Daninha, Viçosa-MG, v. 28, n. 3, p. 615-620, 2010
DAHLBERG, J. A.; BURKE, J. J.; ROSENOW, D. T. Development of a sorghum core collection: refinement and evaluation of a subset from sudan. Econ. Bot., v. 58, n. 4, p. $556-567,2004$

FELIX, J.; DOOHAN, D. J. Response of five vegetables crops to isoxaflutole soil residues. Weed Technol., v. 19, n. 1, p. 391-396, 2005.

GONTIJO NETO, M. M. G. et al. Híbridos de sorgo (Sorghum bicolor (L.) Moench) cultivados sob níveis crescentes de adubação. Rendimento, proteína bruta e digestibilidade in Vitro. R. Bras. Zootec., v. 31, n. 4 , p. $1640-1647,2002$

GROSSMANN, K.; EHRHARDT, T. On the mechanism of action and selectivity of the corn herbicide topramezone: a new inhibitor of 4- hydroxyphenylpyruvate dioxygenase.

Pest Manag., v. 63, n. 3, p. 429-439, 2007.

HORKY, K. T.; MARTIN, A. R. Evaluation of preemergence weed control programs in grain sorghum. In: Weed control in specialty crops. Lincoln: 2005. p. 30-32. (NCWSS Research Report. v. 62)

MILLER, J. N.; REGEHR, D. L. Grain sorghum tolerance to postemergence mesotrione applications. Weed Sci., v. 57, n. 2, p. 136-143, 2002.

MITCHELL, G. D. W. et al. Mesotrione: a new selective herbicide for use in maize. Pest Manag., v. 57, n. 4, p. 120-128, 2001.

MOORE, J. W.; MURRAY, D. S.; WESTERMAN, R. B. Palmer amaranth (Amaranthus palmeri) effects on the harvest and yield of grain sorghum (Sorghum bicolor)

Weed Technol., v. 18, n. 5, p. 23-29, 2004.

NORRIS, R. F. Barnyardgrass [Echinochloa crus-galli (L.) Beauv] competition and seed production. Weed Sci., v. 5, n. 20 , p. $143-149,1980$

PATAKY, J. K. et al. Genetic basis for varied levels of injury to sweet corn hybrids from three cytochrome P450metabolized herbicides. J. Am. Soc. Hortic. Sci., v. 133, n. 1, p. 438-447, 2008.

STAHLMAN, P. W.; WICKS, G. A. Weeds and their control in grain sorghum. In: SMITH, C. W.; FREDERIKSEN, R. A. (Eds.). Sorghum: origin, history, technology, and production New York: John Wiley \& Sons, 2000. p. 535-690

TAMADO, T.; SCHU“TZ, W; MILBERG, P. Germination ecology of the weed Parthenium hysterophorus in eastern Ethiopia. Ann. Appl. Biol., v. 140, n. 3, p. 263-270, 2002.

WADDINGTON, M. A.; YOUNG, B. G. Interactions of herbicides and adjuvants with $\mathrm{AE} 0172747$ on postemergence grass control. Weed Sci., v. 61, n. 4, p. 108-115, 2006 